\title{
Dinâmica de Fragmentos Florestais no Noraeste do Rio Grande do Sul
}

\section{Dynamic of Forest Fragments in the Northwest of Rio Grande do Sul}

\begin{abstract}
Resumo:
O objetivo do trabalho é analisar a dinâmica da cobertura florestal no noroeste do estado do Rio Grande do Sul, Brasil, entre os anos de 1985 e 2014, a partir do uso de imagens dos sensores multiespectrais do Landsat 5 (TM) e 8 (OLI). O resultado indicou um aumento de $50,4 \%$ da área ocupada por florestas de 1985 a 2014. No período de 1985-2005, o número de fragmentos florestais cresceu $156,7 \%$. Verificou-se uma redução de $39,2 \%$ do número de fragmentos remanescentes no período 2005-2014. Em relação ao tamanho dos fragmentos, observa-se uma queda no número de fragmentos muito pequenos $(<5 \mathrm{ha})$ e pequenos $(5 \mathrm{a}$ $10 \mathrm{ha})$ e o aumento do número de fragmentos médios (10 a $100 \mathrm{ha})$ e grandes ( $>100 \mathrm{ha}$ ), principalmente entre 2005 e 2014. As métricas de paisagem (área, densidade e tamanho, forma, borda e área central) indicaram que a região se apresenta muito fragmentada. Entretanto, a mesma está passando por um processo de regeneração florestal, que é um resultado da criação de leis e políticas públicas que promovem a preservação e plantio de florestas e da dinâmica demográfica.
\end{abstract}

\begin{abstract}
:
The objective was to analyze the dynamics of forest cover in the northwest of Rio Grande do Sul State, Brazil, between 1985 and 2014, using Landsat 5 TM and Landsat 8 OLI multispectral images. The results showed an increase of $50.4 \%$ in the area covered by forests between 1985 and 2014. The number of forest fragments grew 156.7\% from 1985 to 2005. A decrease of $39.2 \%$ in the number of fragments was observed from 2005 to 2014. Regarding the size of the fragments, there is a decrease in the number of very small $(<5 \mathrm{ha})$ and small fragments (5 to $10 \mathrm{ha}$ ) and an increase in the number of medium (10 to $100 \mathrm{ha})$ and large fragments (> 100 ha), mainly between 2005 and 2014. The landscape metrics (area, density, size, shape, edge and central area) indicated that the region is very fragmented. However, it is undergoing a process of forest regeneration, which is a result of the creation of laws and public policies that promote the preservation and planting of forests as well as a consequence of demographic dynamics.
\end{abstract}

Paulo Afonso da Rosa * Fábio Marcelo Breunig ** Cláudia Maria de Almeida *** Rafaelo Balbinot ****

* Engenheiro Florestal e Mestre em Geografia pela UFSM.

** Doutorado em Sensoriamento Remoto pelo Instituto Nacional de Pesquisas Espaciais. Prof. do PPGGEOUFSM. Bolsista de Produtividade em Pesquisa 2 do CnpQ

*** Instituto Nacional de Pesquisas Espaciais.

**** Doutorado em Ciências Florestais - Conservação da Natureza pela UFPR. Prof. do Depto de Engenharia Florestal da UFSM

\section{Palavras-chave:}

Mapeamento florestal, Sensoriamento remoto, Fragmentação florestal

Key-Words:

Forest mapping, Remote sensing, Forest fragmentation 


\section{INTRODUÇÃO}

A paisagem é a expressão de processos compostos por uma sequência de mudanças que ocorreram em determinada fração de tempo e espaço, decorrentes da ação de agentes naturais e antrópicos. A cobertura florestal, por ser parte dessa paisagem, tem sua dinâmica própria resultante desses impactos, conduzindo à perda total da vegetação natural e/ou a uma grade de remanescentes. A vegetação é considerada um importante indicador de condições ambientais de uma determinada região, pois tem a função de proteger o solo contra os processos erosivos (COSTA et al., 2014), controlar o microclima de uma região (GALVANI e LIMA, 2010), manter o nível hidrológico, além de servir de abrigo, nidificação e alimentação de diversas espécies animais (GIMENEZ e ANJOS, 2003; GARCIA et al., 2013). Com o crescimento acelerado da população humana e expansão agrícola, tem-se observado um aumento da pressão sobre os fragmentos florestais remanescentes (FIORI et al., 2014; SAITO et al., 2016). Nesse contexto, desenvolver e aprimorar métodos de monitoramento do ambiente, subsidiando com informações atualizadas o planejamento de uso da terra e a recuperação de áreas é fundamental à qualidade dos serviços sistêmicos florestais.

Através do conhecimento da dinâmica temporal da vegetação, é possível identificar padrões, processos e mecanismos, que podem ser usados para realizar predições e orientar estratégias de uso racional, proteção e conservação dos recursos florestais. Entretanto, os métodos propostos para esse tipo de abordagem se diversificam tanto no procedimento técnico empregado como na área de concentração, muitas vezes tornando-os de difícil operacionalização. Dada a velocidade de supressão dos remanescentes florestais, há exigências para se dispor de produtos e métodos capazes de produzir diagnósticos mais precisos das condições dos recursos florestais (DALLA NORA e SANTOS, 2010), com ações de monitoramento em diversas escalas espaciais e de tempo. Nisso se fundamenta o interesse cada vez maior no uso dos ferramentais das geotecnologias espaciais.

Segundo Soares Filho (1998), para estudar a dinâmica da paisagem, é necessário mapear os padrões de uso de cobertura da terra e avaliar como cada elemento da paisagem se relaciona com o outro de forma espacial e temporal. Isso retrata o grau e direção das atividades humanas na paisagem, permitindo uma análise sinóptica da pressão e impacto sobre os elementos naturais de uma dada região, permitindo, inclusive nessa análise, estabelecer melhores informações acerca dos meios biofísicos e socioeconômicos que nela atuam.

Combinando técnicas de geoprocessamento e dados de sensoriamento remoto, é possível elaborar uma caracterização do ambiente, inventariar e gerenciar os elementos da paisagem florestal (FREITAS et al., 2012; SILVA et al., 2014). Essas ferramentas têm sido aplicadas no monitoramento florestal de biomas diversos (ASSIS et al., 2015), quer seja em Áreas de Proteção Ambiental (MICELI et al., 2015), em bacias hidrográficas (SILVA et al., 2015) e monitoramento da cobertura arbórea de Parques Estaduais (SOUZA et al., 2015). Imagens de diferentes sensores remotos, de variadas resoluções espaciais, espectrais e/ou temporais, têm permitido uma análise histórica e atual da distribuição espacial da cobertura florestal remanescente, caracterizando o uso da terra, e inclusive, permitindo através de modelos de dinâmica gerar cenários da paisagem em tempo futuro. Exemplo disso é o trabalho de Freitas e Santos (2014), que integrando variáveis geomorfométricas, métricas da paisagem e sociais, com dados temporais de uso e cobertura da terra obtidos de imagens TM/Landsat, realizaram uma análise hierárquica da paisagem na bacia do Rio Uruguai (RS), inclusive com mensuração e projeção de demandas de uso da terra e cobertura florestal, com geração de cenários assegurando modelos de suporte aos planejadores e tomadores de decisão.

É fato comum, sob a ótica de ecologia, que para tornar possíveis ações que promovam a recuperação de ambientes e até mesmo a interligação de fragmentos florestais, é necessária a realização do diagnóstico atual de uso e cobertura da terra. Nas últimas décadas, alguns autores, conforme citado por HENDGES et al. (2012), têm reportado um aumento da cobertura florestal do noroeste do estado do Rio Grande do Sul. Contudo, essa aparente expansão não é avaliada em termos das métricas da paisagem (forma, tamanho, área, borda, densidade, e área central).

Dentro desse contexto, o objetivo do presente trabalho é analisar a dinâmica da cobertura florestal nessa porção noroeste do Rio Grande do Sul, entre os anos de 1985 e 2014, abrangendo as microrregiões de Frederico Westphalen (FW) e Três Passos (TP). Imagens de satélite da série Landsat são empregadas para permitir, fazendo uso de métricas da paisagem, uma análise da dinâmica dos fragmentos florestais ali ocorrentes.

\section{METODOLOGIA}




\section{1 Área de estudo}

A área de estudo compreende as microrregiões de FW e TP, localizadas no noroeste do estado do Rio Grande do Sul, Brasil (INSTITUTO BRASILEIRO DE GEOGRAFIA E ESTATÍSTICA - IBGE, 2013) (Figura 1). A microrregião de FW possui área de $5.185 \mathrm{~km}^{2}$, constituída por 27 municípios (ARNS E PIOVEZANA, 2008), enquanto a microrregião de TP possui uma área de 3.861 $\mathrm{km}^{2}$, abrangendo 20 municípios. As microrregiões caracterizam-se por possuir temperatura superior a $20^{\circ} \mathrm{C}$ nos meses mais quentes e temperatura inferior a $15^{\circ} \mathrm{C}$ nos meses mais frios, com precipitação pluviométrica anual oscilando entre 1.500 e 1.800 mm, não apresentando cenários de déficit hídrico (IBGE, 1986; SECRETARIA ESTADUAL DO MEIO AMBIENTE DO ESTADO DO RIO GRANDE DO SUL - SEMA/RS, 2005).

A vegetação nativa da área de estudo é constituída predominantemente pela Floresta Estacional Decidual Submontana, representada por dois estratos arbóreos distintos: a) emergente, aberto e decíduo, com altura variando entre 25 e $30 \mathrm{~m}$, e b) dominante e contínuo, com altura inferior a $20 \mathrm{~m}$, formado principalmente por espécies perenifoliadas, além de um estrato de arvoretas. O caráter decidual da floresta é determinado por leguminosas caducifólias, onde se destacam a Apuleia leiocarpa (grápia) e o Parapiptadenia rigida (angico). Além disso, há uma diversificada florística, com aspectos distintos, em função de pequenas variações ambientais determinadas por fatores litológicos, geomorfológicos, edáficos e climáticos (IBGE, 2012).

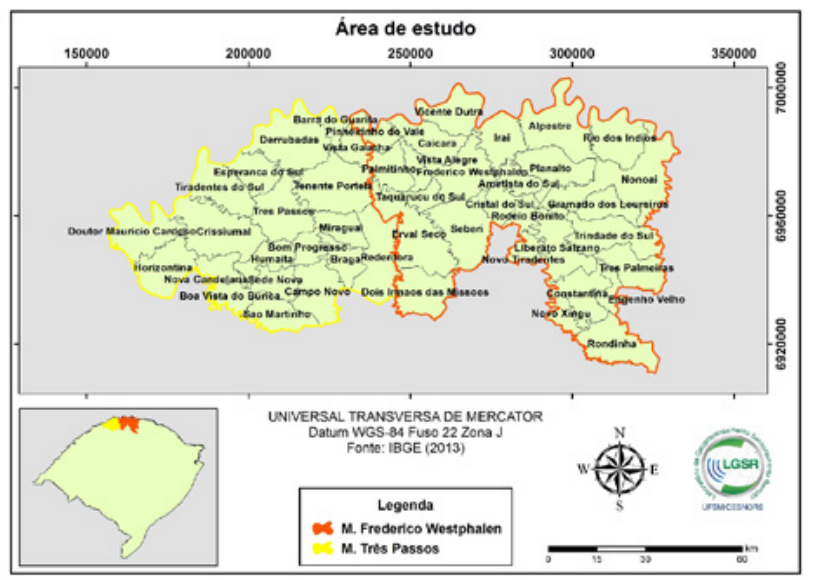

Figura 1: Mapa de localização das microrregiões de FW (identificada pela borda vermelha na figura) e TP (borda amarela), no norte-noroeste do Rio Grande do Sul.

Fonte: : Adaptado de IBGE (2013).
Nessas duas microrregiões, ocorrem três grandes remanescentes florestais, situados em Unidades de Preservação: no Parque Estadual do Turvo (PET) com 17.500 ha (RUSCHEL et al., 2005; RUSCHEL et al., 2007; ROSA et al.; 2013; BREUNIG et al., 2015); nas Terras Indígenas do Guarita (TIG) (23.407 ha); e na de Nonoai (TIN) (19.830 ha) (BREUNIG et al., 2015; ROSA e BREUNIG, 2015). Os demais remanescentes florestais, de menores proporções, estão distribuídos de forma esparsa em toda área de estudo, em meio aos projetos de agricultura e pecuária, principalmente cultivos de milho e soja, a bovinocultura de leite e a suinocultura, praticados em propriedades rurais menores que 50 ha (RIO GRANDE DO SUL, 2015a; 2015b). Na área de estudo, predomina a agricultura familiar. Em geral, a paisagem é bastante fragmentada nos municípios lindeiros aos grandes rios e apresenta uma tendência à monocultura em propriedades rurais maiores nos municípios na borda sul da área de estudo (p. ex., Seberi e Campo Novo).

\subsection{Aquisição e processamento das imagens de sa- télite}

Imagens do Landsat 5 (sensor Thematic Mapper TM) referentes aos anos de 1985, 1994 e 2005, e do Landsat 8 (sensor Operational Land Imager - OLI) do ano de 2014, foram utilizadas no presente trabalho. Foram selecionadas cenas correspondentes ao mesmo período do ano (maio e outubro/novembro), de forma a minimizar os efeitos da interpretabilidade e o efeito da sazonalidade na resposta da cobertura florestal. Todas as cenas foram obtidas da plataforma online Earth Explorer - United States Geological Survey (USGS, 2015). Considerando que a região em estudo é coberta por duas imagens, de órbitas-ponto 222-079 e 223-079, foi realizado um mosaico.

As cenas foram adquiridas do repositório da USGS - United States Geological Survey - no formato Landsat Climate Data Record (CDR). Os dados Landsat CDR são gerados a partir de um software denominado Landsat Ecosystem Disturbance Adaptive Processing System (LEDAPS), desenvolvido originalmente pela NASA - National Aeronautics and Space Administration - que emprega rotinas de correção atmosférica aplicadas às imagens, tendo como dados de entrada as informações de vapor d'água, de ozônio, de espessura óptica de aerossóis e modelos digitais de elevação, para, através de 
modelos de transferência radiativa, gerar dados de reflectância no topo da atmosfera, reflectância de superfície, temperatura de superfície, máscaras de nuvens, sombras de nuvens, terra e água (MAIERSPERGER et al., 2013; MASEK et al., 2006). As imagens Landsat CDR são geradas com resolução espacial de $30 \mathrm{~m}$ em projeção Universal Transversa de Mercator ou Polar Estereográfica (USGS, 2015). As imagens OLI também foram obtidas com a correção geométrica e atmosférica, com resolução espacial de $30 \mathrm{~m}$. Para o mapeamento final, foi utilizada a escala de 1:250.000, devido às limitações das cenas da série do Landsat.

\subsection{Mapeamento da cobertura florestal}

Os fragmentos florestais foram mapeados por interpretação visual (edição manual de polígonos) das imagens, diretamente na tela do computador, por um único fotointérprete, no modo de composições coloridas (3R-2G-1B no caso do sensor Landsat 5 TM; e 4R-3G-2B para o Landsat 8 OLI), conforme os parâmetros fotointerpretativos espectrais e texturais representativos da classe temática em questão (JENSEN, 2009; COELHO E BRITO, 2007). Em caso de dúvida, alguns polígonos foram auditados, utilizando imagens de alta resolução espacial (p. ex., Google Earth ${ }^{\circledR}$ ) e inspeções em campo (áreas próximas às rodovias).

Considerando o foco do estudo, somente a cobertura florestal foi mapeada, por meio de identificação e posterior edição vetorial de polígonos. Considera-se, nesse estudo, a cobertura florestal como um todo, incluindo remanescentes de mata nativa em suas diversas sucessões, plantios florestais, áreas reflorestadas e florestas degradadas. As demais classes de uso e cobertura da terra foram agrupadas em "Outros usos" da terra.

Com o auxilio da tabela de atributos, contendo a área de cada polígono mapeado, os fragmentos florestais foram classificados segundo seu tamanho, sendo: fragmentos muito pequenos (menores que $5 \mathrm{ha}$ ); fragmentos pequenos (de 5,01 a 10 ha); fragmentos médios (de 10,01 a 100 ha); e fragmentos grandes (maiores que 100,01 ha). Devido à resolução espacial e espectral das imagens, não foi possível identificar e diferenciar as formações florestais nativas dos plantios comerciais de árvores, bem como fragmentos florestais muito pequenos menores que um pixel: $900 \mathrm{~m}^{2}$ ). Para avaliar a acurácia temática, algumas inspeções em campo foram conduzidas para áreas próximas às rodovias. Quanto à acurácia posicional, o erro típico dos produtos Landsat foi assumido e tolerado.

\subsection{Métricas de paisagem}

Para o procedimento de análise dos fragmentos florestais, tendo-se como base as informações de número, tamanho, formato e grau de proximidade entre os fragmentos mapeados, foram utilizados índices de ecologia da paisagem, contidos na extensão Patch Analyst, dentro do aplicativo ArcMap (ESRI INC., 2014). As 11 métricas da paisagem analisadas neste estudo são apresentadas na Tabela 1, distribuídas em cinco grupos: área, densidade e tamanho, borda, forma, e área central. Esses índices também foram considerados em estudos de Juvanhol et al. (2011) e Pirovani et al. (2014).

Tabela 1. Métricas de paisagem utilizadas no estudo

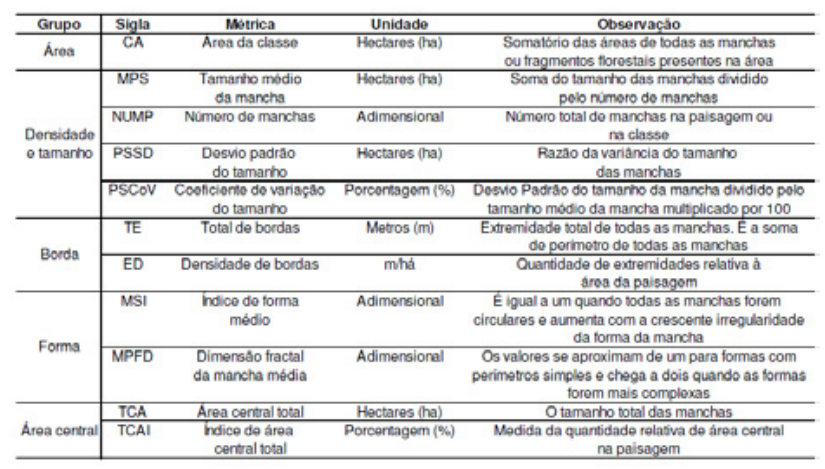

Fonte: : Adaptado de McGarigal e Marks (1995).

Para o cálculo das métricas de paisagem, foram utilizados os arquivos de fragmentação no formato shapefile. A distância de $60 \mathrm{~m}$ de borda foi adotada como padrão para o cálculo do índice de área central (PEREIRA et al., 2001; BORGES et al., 2004).

\subsection{Análise dos dados}

A partir do mapeamento multitemporal dos fragmentos florestais, foram obtidas as estatísticas de número e área dos fragmentos florestais para toda a região em estudo, para cada uma das microrregiões e individualmente para os municípios, considerando cada data mapeada. Os resultados são descritos na forma de tabelas, gráficos e figuras, buscando representar da melhor maneira possível o comportamento da cobertura arbórea nos anos de 1985, 1994, 2005 e 2014.

Para identificar as áreas com ganhos e perdas de cobertura florestal, foram elaborados mapas de transição, de forma a ressaltar as diferenças positivas e negativas (em relação à cobertura florestal) em distintos intervalos de tempo. Assim, foi possível identificar os locais que não tiveram au- 
mento de área florestada (conservação), locais que apresentaram aumento de área florestada (evolução) e locais em que houve um decréscimo de área florestada (supressão). Em relação às métricas da paisagem, foram obtidas as estatísticas da região como um todo, sem distinção de microrregiões, para cada ano mapeado, gerando perfis temporais de ecologia de paisagens.

\section{RESULTADOS}

\subsection{Análise da cobertura florestal em função do ma- peamento multitemporal}

O mapeamento da fragmentação florestal a partir da análise visual das imagens de satélite demonstrou um aumento gradual de área de cobertura florestal nas microrregiões de FW e TP entre os anos de 1985 e 2014 . A Figura 2 ilustra os resultados obtidos para cada ano de estudo em cada microrregião. De 1985 a 2014, a cobertura arbórea da região teve um aumento de área de 50,4\%, considerando a área florestal. Isso pode ser explicado por dois fatores: um processo natural de êxodo rural que ocorreu na região, principalmente em busca de centros industriais; e a modernização da agricultura, que limitou a prática em terrenos declivosos, o que é característico da região de estudo. Dessa maneira, terrenos declivosos serviram para a regeneração natural da floresta, ou então, foram utilizados para plantios comerciais de árvores (KOUCHER, 2006; MEDEIROS, 2005; ROSA et al., 2017).

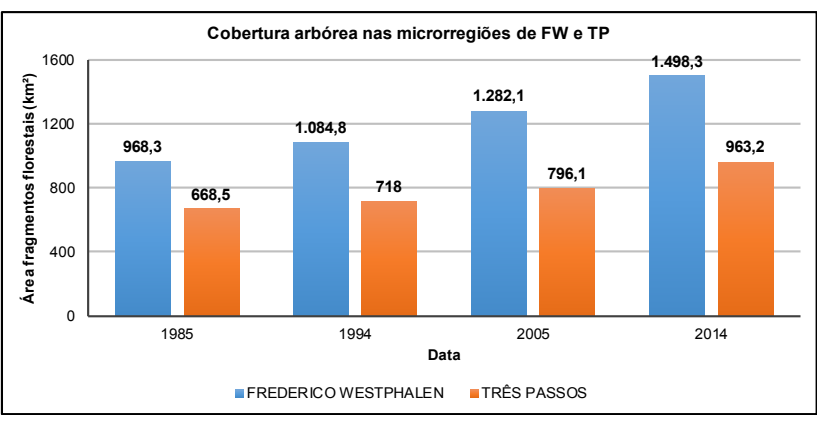

Figura 2: Área total dos fragmentos florestais para cada microrregião de estudo para o período de 1985 a 2014.

Fonte: Dados obtidos do mapeamento manual utilizando imagens da série de satélites Landsat.

O número de fragmentos florestais aumentou de 1985 a 2005; entretanto, de 2005 a 2014, houve um decréscimo (Tabela 2). Esse decréscimo no número de fragmentos pode ser explicado pela união de dois ou mais pequenos fragmentos que estavam próximos e passaram a formar um único fragmento de maior dimensão, ou mesmo, limitações associadas à interpretação de imagens de média resolução espacial.

Figura 3: Mapa gerado pelos pontos georreferenciados no Balneário do Córrego das Pedras. No canto superior esquerdo da figura se observa duas alunas trabalhando com aparelho GPS.

\begin{tabular}{crrrr}
\hline MICRORREGIÄO & $\mathbf{1 9 8 5}$ & $\mathbf{1 9 9 4}$ & $\mathbf{2 0 0 5}$ & $\mathbf{2 0 1 4}$ \\
\hline Frederico Westphalen & 5.016 & 13.817 & 16.138 & 9.703 \\
Três Passos & 5.016 & 9.144 & 9.612 & 5.972 \\
\hline TOTAL & 10.032 & 22.961 & 25.750 & 15.675 \\
\hline
\end{tabular}

Fonte: Dados obtidos do mapeamento manual utilizando imagens da série de satélites Landsat.

De 1985 a 2005, o número de fragmentos florestais na região de estudo teve um crescimento de 156,7\% (10.032 para 25.750). Entretanto, de 2005 a 2014, o número de fragmentos teve um decréscimo de 39,1\% (25.750 para 15.675 fragmentos). Comparando o número de fragmentos de cada microrregião, constatou-se um grande salto no número de fragmentos da microrregião de FW entre 1985 e 2005, com um incremento de 11.122 fragmentos em 20 anos, enquanto a microrregião de TP teve um incremento de 4.596 fragmentos no mesmo período. Uma hipótese para explicar o pequeno aumento dos fragmentos na microrregião de TP em relação à FW é a menor dimensão territorial da microrregião e o uso agrícola intensivo em propriedades maiores, dadas as características geomorfológicas favoráveis à agricultura.

Nas Figuras 3 e 4, é possível visualizar a representação da fragmentação florestal em 1985 e 2014, respectivamente. Notoriamente, o mapa de 2014 apresenta "um tom mais verde" em relação ao de 1985, principalmente na microrregião de FW. Esse padrão de incremento da cobertura florestal está associado ao abandono de áreas agrícolas, redução da população rural, cumprimento da legislação ambiental e ao aumento da cobertura florestal de espécies comerciais (ROSA et al., 2017).

A análise da fragmentação florestal permitiu obter resultados de fragmentos por classes de tamanho para cada microrregião de estudo (Figura 5). As Figuras 5a e $5 b$ exibem os resultados para as microrregiões de FW e TP, respectivamente. Observa-se que, apesar de a microrregião de TP ter uma menor dimensão territorial, ela apresenta maior número de fragmentos florestais muito pequenos (área $<5 \mathrm{ha}$ ), com 32,3\% mais fragmentos que a microrregião de FW no ano de 1985. Entretanto, nas demais classes de tamanho, a microrregião de FW apresenta maior número de fragmentos. Isso mostra que o uso agrícola mais intenso vem provocando uma forte pressão sobre os fragmentos florestais de pequeno porte, 
podendo levar a sua eliminação. Nos fragmentos pequenos (de 5 a 10 ha), a microrregião de FW possui 13,6\% mais fragmentos que TP; nos fragmentos médios (de 10 a $100 \mathrm{ha}$ ) essa diferença aumenta para 57,5\%. Nos fragmentos grandes (área > 100 ha), a microrregião de FW possui $162,5 \%$ mais fragmentos que a microrregião de TP.

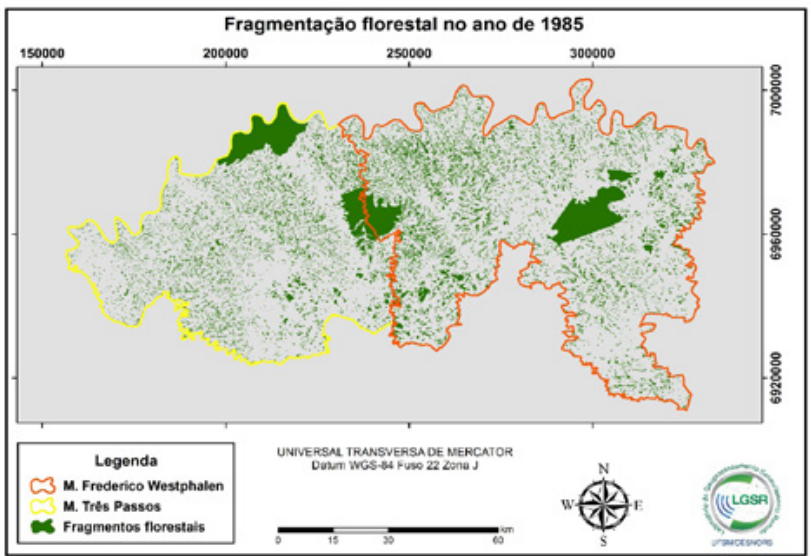

Figura 3: Distribuição dos fragmentos florestais no ano de 1985 nas microrregiões de Frederico Westphalen e Três Passos.

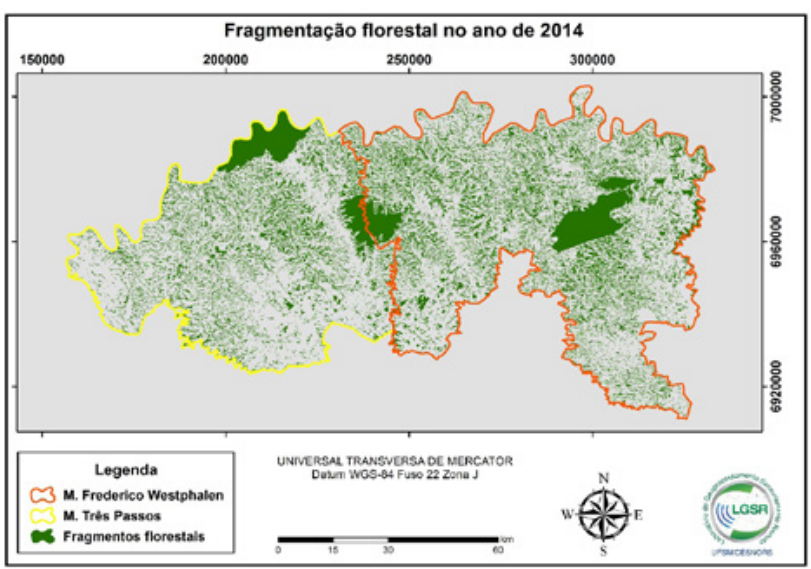

Figura 4: Distribuição dos fragmentos florestais no ano de 2014 nas microrregiões de Frederico Westphalen e Três Passos.

No ano de 1994, constata-se um grande aumento no número de fragmentos florestais muito pequenos e pequenos e um decréscimo de fragmentos médios e grandes em relação ao ano de 1985. A microrregião de Frederico Westphalen, assim como observado no ano de 1985, apresenta um número maior de fragmentos florestais em relação a Três Passos, da ordem de 50\% nos fragmentos muito pequenos; $50,2 \%$ nos fragmentos pequenos; $57,9 \%$ nos fragmentos médios e $57,5 \%$ nos fragmentos grandes.
No ano de 2014, houve uma brusca queda no número de fragmentos em relação ao ano de 2005. Para os fragmentos muito pequenos, a queda foi de $52,8 \% \mathrm{em}$ FW e $55,4 \%$ em TP. O mesmo ocorreu com os fragmentos pequenos, apresentando uma queda de $25,7 \% \mathrm{em}$ FW e 23,8\% em TP. Entretanto, os fragmentos médios apresentaram aumento de 5\% em FW e 21,5\% em TP; enquanto os fragmentos grandes aumentaram $200 \% \mathrm{em}$ FW e $258,8 \%$ em TP.

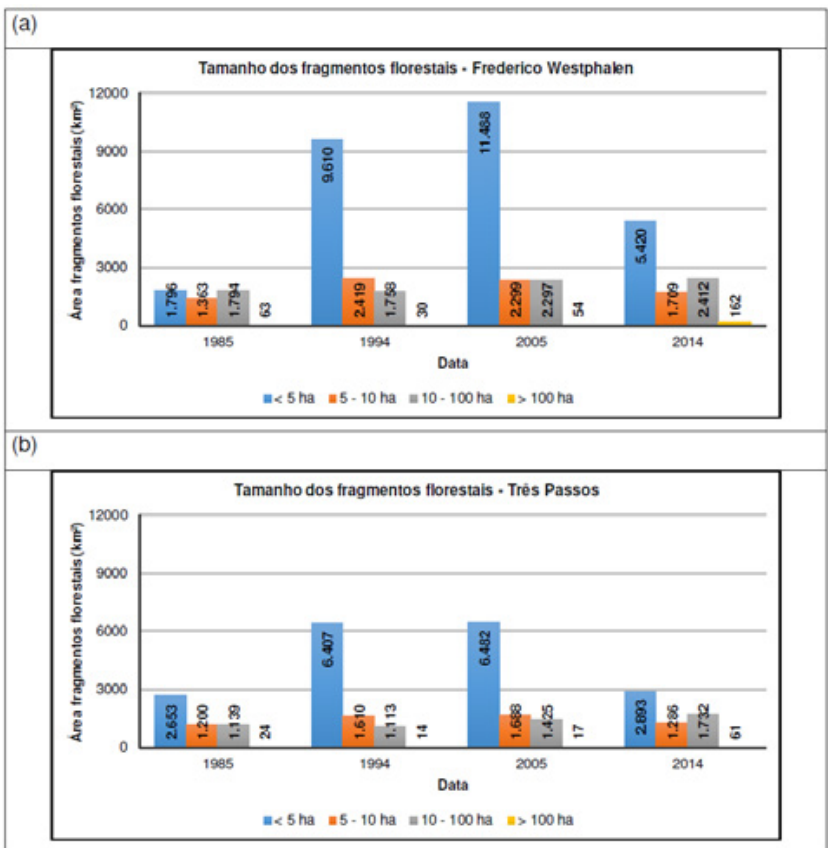

Figura 5: Evoluçao do tamanno dos tragmentos Horesta1s para as m1crorregiões de (a) FW e (b) TP.

Esses resultados comprovam que a microrregião de TP apresenta condições mais favoráveis à prática da agricultura, ou seja, são áreas mais planas e aptas para o cultivo mecanizado. Até o ano de 1984, boa parte da cobertura florestal que existia nessas áreas foi removida para a expansão da fronteira agrícola. $\mathrm{Na}$ microrregião de FW, as condições geomorfológicas são diferentes, a topografia regional é mais acidentada. Isso se comprova pelo maior número de fragmentos acima de 5 ha. Outro fator nesse sentido é o aumento muito superior no número de fragmentos na microrregião de FW de 1985 até 2005, em função do abandono das áreas agrícolas que não poderiam ser mecanizadas. Novamente, em função das características topográficas, houve grande abandono de áreas e, contrariamente, na microrregião de TP, não havia muitas áreas inaptas para a mecanização, logo, o abandono das áreas de produção foi menor.

Comparando a fragmentação florestal de 1985 e 
2014, observa-se claramente um aumento significativo de fragmentos médios $(10$ - 100 ha). Em relação aos fragmentos grandes, também se pode visualizar o aumento do número de fragmentos, sobretudo na microrregião de FW. Aparentemente, até a década de 1990, houve uma menor recuperação de áreas, e a partir de 2000, ocorre uma maior recuperação de áreas florestais nativas (HENDGES et al., 2012) ou plantios comerciais. Essa maior recuperação de áreas levou a uma consolidação de alguns fragmentos e, até mesmo, a sua expansão, agrupando outros fragmentos. Assim, verificou-se no mapeamento de 2014 que o número de fragmentos identificados foi menor que nas décadas anteriores, apesar do aumento da área florestal.

A análise da transição de fragmentos florestais entre 1985 e 2014 é ilustrada quantitativamente e espacialmente na Figura 6, que indica um ganho quantitativo florestal de $1.258 \mathrm{~km}^{2}$. Da mesma forma, foi espacialmente constatado que certos fragmentos mapeados em 1985 não foram identificados integralmente no mapeamento de 2014, totalizando uma perda em área de 433 $\mathrm{km}^{2}$. Observa-se uma perda significativa de cobertura florestal nas bordas das unidades de conservação (PET, TIG e TIN) (Figura 6).

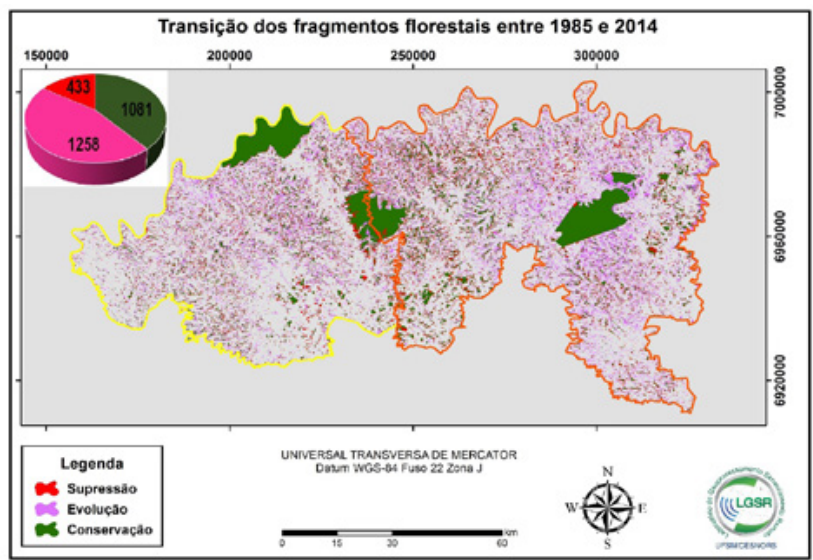

Figura 6: Espacialização da transição de cobertura florestal no período de 1985 a 2014. O gráfico no modo "pizza" indica as perdas e ganhos em $\mathrm{km}^{2}$ para o período analisado (1985-2014).

\subsection{Análise da cobertura florestal em função das mé- tricas de paisagem}

Assim como no processo de mapeamento, o estudo de métricas de paisagem permitiu observar o aumento da área florestal da região (Figura 7a). De 1985 a 1994, houve uma queda de 15.726,4 ha de floresta, porém, de 1994 a 2014, houve um aumento de área florestal de 41.342,7 ha. O tamanho médio da mancha apresentou oscilações nos anos analisados, apresentando em 1985 uma área média de 7,6 ha; nos anos subsequentes, a área média da mancha diminuiu para 4,2 ha, ao passo que no ano de 2014 a área média foi de 6,6 ha (Figura 7b). McGarigal et al. (2002) salientam que o tamanho médio dos fragmentos (MPS) é considerado bom indicativo do grau de fragmentação, por ser função do número de fragmentos e da área total ocupada pela classe. Dessa forma, paisagens que apresentam menores valores para tamanho médio de fragmento devem ser consideradas como mais fragmentadas. Em relação ao desvio padrão do tamanho da mancha (PSSD), ocorreu uma pequena queda no decorrer do tempo, de $253 \mathrm{em} 1985$ para 220,8 em 2015. Estes valores são considerados altos e indicam uma grande variação nos tamanhos dos fragmentos, ou seja, manchas com valores de área muito acima e/ou muito abaixo do valor médio. De acordo com Pereira et al. (2007), o tamanho médio dos fragmentos deve ser analisado examinando-se o desvio padrão; se este for muito grande, é possível que haja grandes fragmentos, mesmo com um tamanho médio relativamente baixo. No presente trabalho, o alto valor observado do desvio padrão é explicado pela presença de três grandes fragmentos florestais encontrados em unidades de proteção ambiental, embora a predominância de fragmentos concentre-se em tamanhos pequenos.

O número de fragmentos florestais foi outro elemento importante no estudo. Conforme resultados encontrados através das métricas de paisagem (Figura 7c), o número de fragmentos florestais apresentou crescimentos sucessivos entre 1985 e 2005, tendo uma pequena queda entre 2005 e 2014. No entanto, o crescimento em relação a 1985 foi de 51,3\%. Segundo Casimiro (2000), quanto maior a subdivisão da paisagem, maior o número de manchas, maior a resistência potencial à propagação de perturbações como doenças e fogo, podendo as manchas persistir mais facilmente do que se o número das mesmas fosse diminuto.

Os efeitos de borda vêm sendo conceituados como alterações nas condições ecológicas decorrentes da interação da paisagem. À medida que os fragmentos se tornam menores e com forma mais irregular, eles se tornam progressivamente dominados pelos habitats de borda (CASTRO, 2008). As métricas de borda (Figura 7d) revelaram um aumento do total de bordas nas da- 
tas analisadas, de $8.171,32 \mathrm{~km}$ em 1985 para 12.390,34 $\mathrm{km}$ em 2014, um aumento de 51,6\%. Esses resultados revelam o elevado grau de fragmentação da região, pois quanto maior o total de margens, maior a fragmentação da paisagem.
A importância das bordas é elevada, pois há uma importante interação da flora e da fauna nestas áreas, que podem constituir habitats por si só, além de serem claramente frentes de interface: predação e refúgio, dispersão de sementes e recolonização, proteção do vento etc. (HOLANDA et al., 2010).
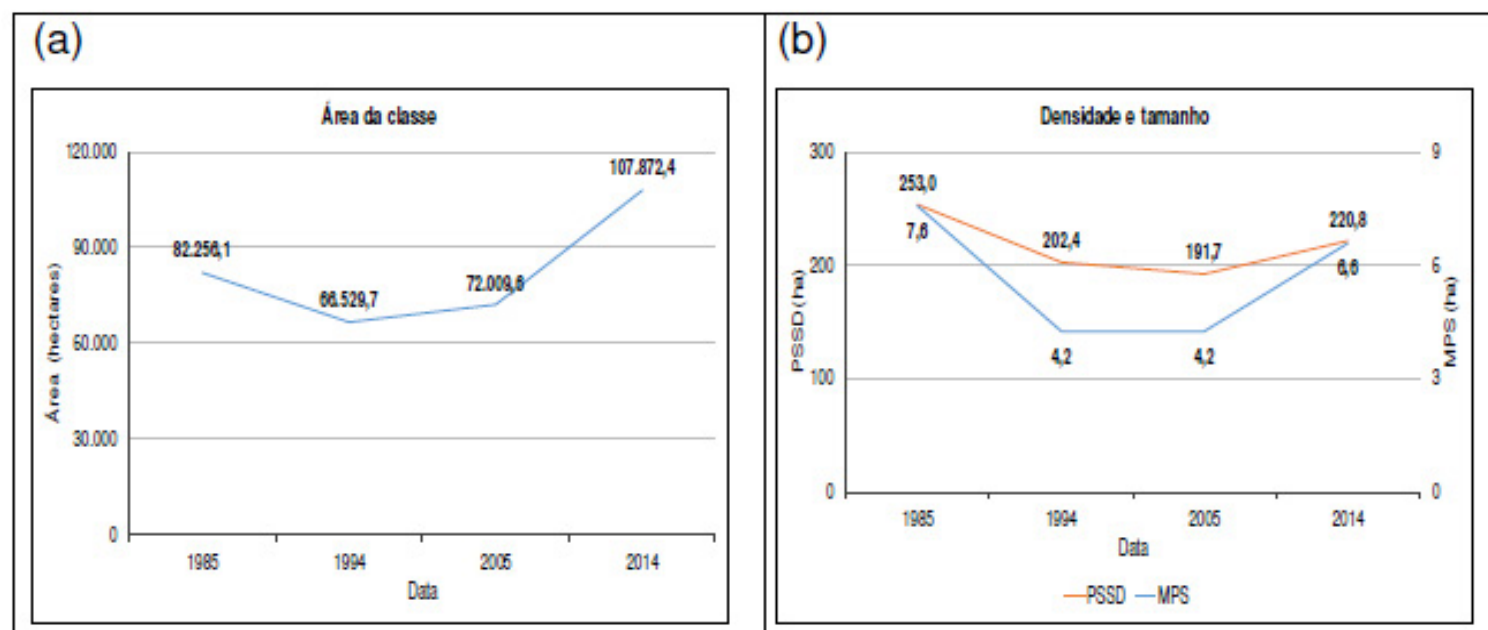

(c)

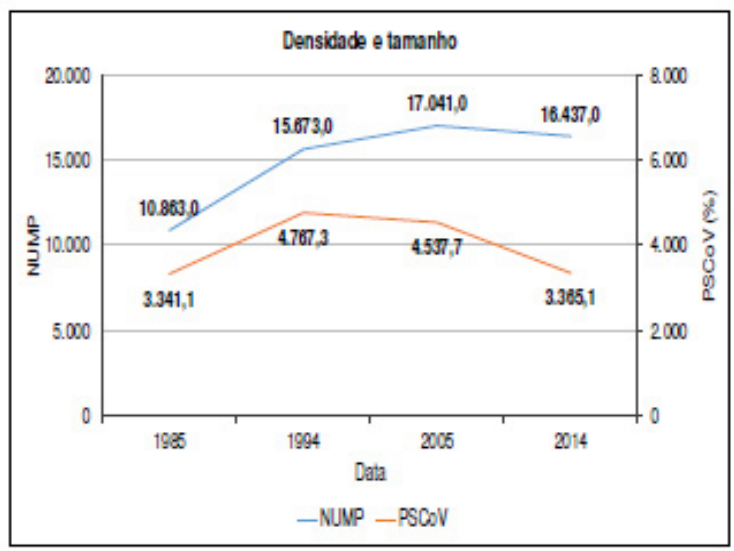

(e)

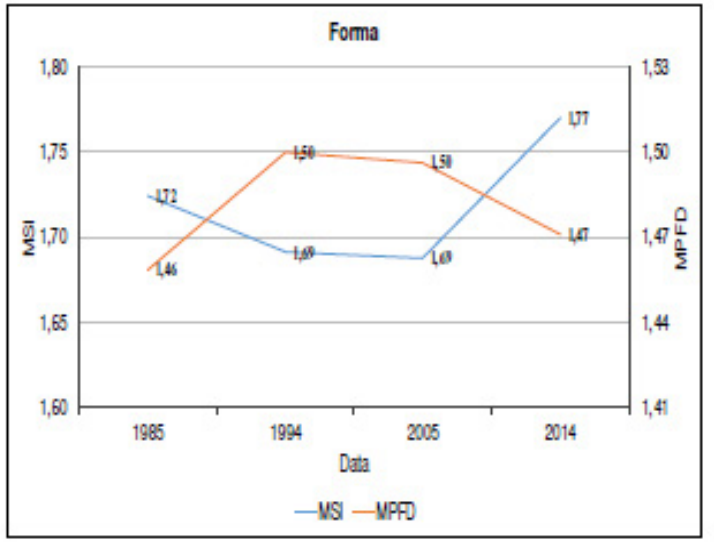

(d)

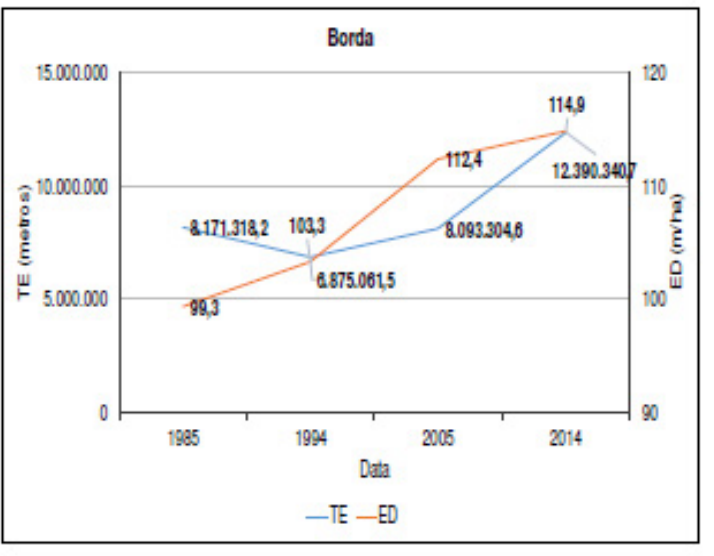

(f)

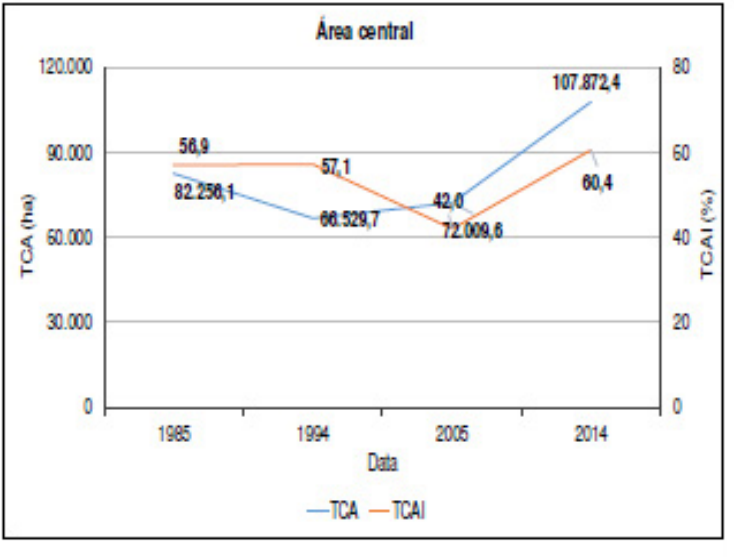

Figura 7: Evolução das métricas de paisagem calculadas para a região de estudo, englobando as duas microrregiões (FW e TP). 
Juntamente com o total de bordas, houve o aumento dos índices de densidade de bordas de 15,7\% entre 1985 e 2014. O aumento dos índices das métricas de borda está relacionado ao aumento do número e tamanho dos fragmentos florestais, que ocupam cada vez mais área na paisagem.

Conforme o exposto, pode-se dizer que quanto maior for a fragmentação da mancha, maior será o aumento das áreas de borda de um habitat. A fragmentação favorece não apenas o desenvolvimento de espécies de borda, muitas vezes predadores e parasitas, mas também de espécies generalistas que tendem a excluir, por competição ou predação, as espécies de interior (METZGER, 1999). Neste sentido, Borges (2010) ressalta que quanto maior o valor da relação perímetro/área, maior o efeito de borda, o que é negativo em termos de preservação.

Ainda de acordo com os resultados, pode-se inferir que houve aumento no número de fragmentos e no tamanho médio destes fragmentos. Apesar disto, estes fragmentos possuem grandes áreas de borda, cujo efeito ecológico para a conservação da paisagem passa a ser afetado negativamente; em outras palavras, houve um aumento do número e tamanho dos fragmentos, tornando a paisagem muito "recortada", com os efeitos de borda reduzindo os ganhos para a manutenção da biodiversidade e conservação da paisagem.

Em relação às métricas de forma, não houve grandes variações durante os anos analisados. De uma forma geral, os fragmentos florestais da região de estudo apresentam formas regulares e perímetros complexos (Figura $7 \mathrm{e})$.

O índice de área central (ou área core) calculado corresponde à porção da mancha que não é afetada pelos efeitos de borda, ou seja, corresponde à área nuclear do fragmento de vegetação arbórea (MCGARIGAL et al., 2002). As métricas de áreas centrais (Figura 7f) apresentam um aumento na área total das manchas, de 82.256,1 ha em 1985 para 107.872,4 ha em 2014, um aumento de $31,1 \%$. Da mesma forma, o índice de manchas cresceu na região de 56,9\% em 1985 para 60,4\% em 2014. Isso significa que aproximadamente $40 \%$ dos fragmentos da área de estudo estão submetidos ao efeito de borda. Segundo Borges (2010), a área central reforça o núcleo da expressiva cobertura vegetal. Quanto maior a área central, mais equilibrado é o ecossistema ali presente.

De acordo com os resultados apresentados, apesar da região estar bastante fragmentada, a mesma está passando por um processo de regeneração florestal, fato que indica positivamente a criação de políticas públicas que incentivam a preservação das matas nativas, o plantio de florestas equiâneas e a formação de corredores ecológicos.

\section{CONCLUSÕES}

O mapeamento da cobertura florestal aponta um aumento de 50,4\% da área ocupada por florestas entre 1985 e 2014. O número de fragmentos florestais cresceu $156,7 \%$ de 1985 a 2005, apresentando, porém, uma redução de 39,2\% no período 2005-2014, provavelmente causado pela união de dois ou mais pequenos fragmentos originando um fragmento maior.

Em relação ao tamanho dos fragmentos, o estudo constatou um crescente aumento de fragmentos médios e grandes. A análise de transição espacial dos fragmentos florestais contabilizou ganho de área de $1.258,1 \mathrm{~km}^{2} \mathrm{e}$ perda de $433,4 \mathrm{~km}^{2}$.

Em geral, os resultados obtidos neste estudo apontam para uma região bastante fragmentada em termos de cobertura florestal, porém, em processo de recuperação, indicando um aumento de cobertura arbórea, fato que se relaciona à mudanças tecnológicas na agricultura, à realidade demográfica da região e à conscientização ambiental.

Cabe destacar que o estudo foi conduzido com base em imagens de média resolução espacial. Assim, fragmentos muito pequenos $(<1$ pixel) não puderam ser identificados. Outra limitação diz respeito às acurácias posicional e temática, que devem ser mais bem avaliadas em estudos futuros.

\section{AGRADECIMENTOS}

Os autores agradecem à NASA - Land Processes Distributed Active Archive Center (LPDAAC) pela disponibilidade dos dados Landsat. À Universidade Federal de Santa Maria (UFSM), pela assistência aos estudos de pós-doutorado. Os autores agradecem também ao Conselho Nacional de Desenvolvimento Científico e Tecnológico (CNPq) (Processos n $n^{\circ} 478085 / 2013-3, n^{\circ} 168869 / 2014-4$ e n $305914 / 2014$ ().

\section{REFERÊNCIAS BIBLIOGRÁFICAS}

ARNZ, Carlos Eduardo; PIOVEZANA, Leonel. "Desen- 
volvimento econômico na microrregião de Frederico Westphalen (RS)". Revista Grifos, n. 24, p. 61-74, 2008.

ASSIS, Tamiris de; COUTO JUNIOR, Antonio Felipe; NEVES, Glauber das; REATTO, Adriana; MARTINS, Eder de Souza; GOMES, Marisa Prado; SENA-SOUZA, João Paulo; REIS, Alexandre Messias; RAMALHO, Lucas Sousa; CLAUDINO, Vander Célio de Matos. "Evolução temporal da cobertura da terra de uma bacia experimental do Cerrado utilizando sensoriamento remoto multisensor e multitemporal". In: XVI SIMPÓSIO BRASILEIRO DE SENSORIAMENTO REMOTO, 2013, Foz do Iguaçu. Anais. Foz do Iguaçu: INPE, 2013. p. 7739-7745.

BORGES, Júnia Lúcio de Castro; CARVALHO, Grazielle Anjos; MOURA, Ana Clara Mourão; NASCIMENTO, Jaqueline. "Estudo da conformação da paisagem de Sabará-MG para compreensão das métricas do fragstats em padrões de uso do solo". In: XXIV CONGRESSO BRASILEIRO DE CARTOGRAFIA, 2010, Aracaju. Anais. Aracaju, 2010. p. 1473-1481.

BORGES, Luís Fernando Rocha; SCOLFORO, José Roberto; OLIVEIRA, Antônio Donizette de; MELLO, José Márcio de; ACERBI JUNIOR, Fausto Weimar; FREITAS, Guilherme Dias de. "Inventário de fragmentos florestais nativos e propostas para seu manejo e o da paisagem". Cerne, v. 10, n. 1, p. 22-38, 2004.

BREUNIG, Fábio Marcelo; GALVÃO, Lênio Soares; SANTOS, João Roberto dos; GITELSON, Anatoly A.; MOURA, Yhasmin Mendes de; TELES, Thiago Sousa; GAIDA, William. "Spectral anisotropy of subtropical deciduous forest using MISR and MODIS data acquired under large seasonal variation in solar zenith angle". International Journal of Applied Earth Observation and Geoinformation, v. 35, p. 294-304, 2015.

BREUNIG, Fábio Marcelo; GALVÃO, Lênio Soares; FORMAGGIO, Antonio Roberto. "Caracterização espectral e temporal da vegetação nativa do Parque Estadual do Turvo e da Terra Indígena do Guarita - RS, com produtos MODIS". In: XV SIMPÓSIO BRASILEIRO DE SENSORIAMENTO REMOTO, 2011, Curitiba. Anais. Curitiba: INPE, 2011, p. 1765-1772.

CASIMIRO, Pedro Cortesão. "Uso do solo - ecologia da paisagem, perspectivas de uma nova abordagem do estudo da paisagem em geografia”. GeoInova, v. 2, p. 45-65, 2000.
COELHO, Luiz; BRITO, Jorge Nunes. Fotogrametria Digital. EdUERJ: Rio de Janeiro, 2007. 196p.

COSTA, Yasmmin Tadeu; BARCELOS, Anna Carolina; RODRIGUES, Sílvio Carlos. "Avaliação da eficiência da cobertura vegetal sobre o processo de escoamento superficial por meio de parcelas experimentais na Fazenda Experimental do Glória (Uberlândia - MG)". In: I SIMPÓSIO MINEIRO DE GEOGRAFIA, 2014, Alfenas. Anais. Alfenas: Universidade Federal de Alfenas, 2014. p. 1-11.

COUTO, Paula. "Análise factorial aplicada a métricas da paisagem definidas em FRAGSTATS". Investigação Operacional, v. 24, p. 109-137, 2004.

DALLA NORA, Elói Lennon; SANTOS, José Eduardo dos. "Análise da dinâmica sazonal de duas formações florestais do Bioma Mata Atlântica com base em índices de vegetação". Perspectiva, v. 34, n. 125, p. 41-51, 2010.

Environmental Systems Research Institute. ESRI. ArcGIS 10.2.2 (Software). Disponível em <http:/ /www.esri.com/ software/arcgis>. 2014.

FIORI, Diana; CEMIN, Gisele; SCHNEIDER, Vânia Elisabete; PÉRICO, Eduardo. "Avaliação temporal da cobertura vegetal no município de Vila Flores-RS". In: IV CONGRESSO INTERNACIONAL DE TECNOLOGIAS PARA O MEIO AMBIENTE. Anais, 2014, p. 1-7.

FREITAS, Daise Moura de; DELGADO, Rafael Coll; RODRIGUES, Rafael de Ávila; SOUZA, Leonardo Paula de. "Variabilidade espaço-temporal na mudança da paisagem no município de Acrelândia, AC”. Enciclopédia Biosfera, v.8, n.14, p. 935-946, 2012.

FREITAS, Marcos Wellausen Dias de; SANTOS, João Roberto dos. "Zoneamento hierárquico da paisagem nos domínios da bacia do Rio Uruguai". Sociedade \& Natureza, v. 26, p. 287-300, 2014.

GALVANI, Emerson; LIMA, Nádia G. B de. "Caracterização microclimática dos manguezais da Barra do Ribeira - Iguape/SP e suas relações com os aspectos fisionômicos da vegetação". GEOUSP - Espaço e Tempo, n. 20, p. 79 - 100, 2006.

GARCIA, Laline da Silva; SANTOS, Alex Mota dos; FOTOPOULOS, Igor Giorgios; FURTADO, Ronei da Silva. 
"Fragmentação florestal e sua influência sobre a fauna: Estudo de Caso na Província Ocidental da Amazônia, Município de Urupá, Estado de Rondônia”. In: XVI SIMPÓSIO BRASILEIRO DE SENSORIAMENTO REMOTO, 2013, Foz do Iguaçu. Anais. Foz do Iguaçu: INPE, 2013, p. 3163-3170.

GIMENES, Márcio Rodrigo; ANJOS, Luiz dos. "Efeitos da fragmentação florestal sobre as comunidades de aves". Acta Scientiarum. Biological Sciences, v. 25, n. 2, p. 391-402, 2003.

JENSEN, John R. Sensoriamento Remoto do Ambiente: Uma Perspectiva em Recursos Terrestres. Ed. Parêntese: São José dos Campos, 2009. 598p.

HENDGES, Elvis Rabuske; PEREIRA, Rudiney Soares; ANDRES, Juliano. "Dinâmica das áreas de floresta nativa no Rio Grande do Sul no período de 1988 a 2020”. Ciência Rural, v. 42, n. 5, p. 828-833, 2012.

HOLANDA, Alan Caue de; FELICIANO, Ana Lúcia Patriota; MARANGON, Luiz Carlos; SANTOS, Moisés Silva dos; MELO, Cybelle Laís Souto Maior Sales de; PESSOA, Mayara Maria de Lima. "Estrutura de espécies arbóreas sob efeito de borda em um fragmento de floresta estacional semidecidual em Pernambuco". Revista Árvore, v. 34, n. 1, p. $103-114,2010$.

INSTITUTO BRASILEIRO DE GEOGRAFIA E ESTATÍSTICA - IBGE. Base Cartográfica Contínua do Brasil na escala 1:250.000. Diretoria de Geociências, 2013.

INSTITUTO BRASILEIRO DE GEOGRAFIA E ESTATÍSTICA - IBGE. Folha SH. 22 Porto Alegre e parte das folhas SH. 21 Uruguaiana e SI. 22. Lagoa Mirim: geologia, geomorfologia, pedologia, vegetação, uso potencial da terra. Rio de Janeiro, 1986.796 p.

INSTITUTO BRASILEIRO DE GEOGRAFIA E ESTATÍSTICA - IBGE. Manual técnico da vegetação brasileira. Rio de Janeiro: IBGE, 2012. 271 p.

JUVANHOL, Ronie Silva; FIEDLER, Nilton Cesar; SANTOS, Alexandre Rosa dos; PIROVANI, Daiani Bernardo; LOUZADA, Franciane Lousada Rubini de Oliveira; DIAS, Henrique Machado; TEBALDI, André Luiz Campos. "Análise espacial de fragmentos florestais: caso dos Parques Estaduais de Forno Grande e Pedra Azul, estado do Es- pírito Santo. Floresta e Ambiente, v. 18, n. 4, p. 353-364, 2011.

KOUCHER, A. B. Migrações internas no Rio Grande do Sul: os novos cenários da desconcentração espacial urbano-regional. 2006. 171 f. Dissertação (Mestrado em Sociologia) - Universidade Federal do Rio Grande do Sul, Porto Alegre, 2006.

MCGARIGAL, Kevin; MARKS, Barbara J. Fragstats: Spatial pattern analysis program for quantify in glandscape structure. Reference manual. For. Sci. Dep. Oregon State University. Corvallis Oregon 59 p.+ Append. 1995.

MCGARIGAL, K., et al. Fragstats: Spatial pattern analysis program for categorical maps - version 3.3 build 5. Manual do programa. Computer software program produced by the authors at the University of Massachusetts, Amherst, 2002.

MAIERSPERGER, T. K., et al. Characterizing LEDAPS surface reflectance products by comparisons with AERONET, field spectrometer, and MODIS data. Remote Sensing of Environment, v. 136, p. 1-13. 2013.

MASEK, Jeffrey G.; VERMOTE, Eric F.; SALEOUS, Nazmi E; WOLFE, Robert; HALL, Forrest G.; HUEMMRICH, Karl F; GAO, F.; KUTLER, Jonathan; LIM, Teng-Kui. "A landsat surface reflectance dataset for North America, 1990-2000". IEEE Geoscience and Remote Sensing Letters, v. 3, n. 1, p. 68-72. 2006.

MATHER, Paul. M. Computer processing of remotely-sensed images: an introduction. 2 ed., Great Britain: John Wiley \& Sons, 1999. 210p.

MEDEIROS, R. M. V. "As formas de produção no Rio Grande do Sul e sua relação com a emigração rural". Agrária, n. 2, p. 69-92, 2005.

METZGER, Jean Paul. "Estrutura da Paisagem e Fragmentação: Análise Bibliográfica". Anais. Academia Brasileira de Ciências. v.71, n. 3-I, 445-463, 1999.

MICELI, Bruna Santos; FERNANDES, Manoel do Couto; ESTRADA, Alessa Favero Duque. "Análise temporal da cobertura e uso da terra através de observações em superfície modelada na APA Petrópolis, Rio de Janeiro”. Geo 
UERJ, n. 26, p. 211-225, 2015.

PEREIRA, Jorge Luis Gavina; BATISTA, Getulio Teixeira; THALÊS, Marcelo; ROBERTS, Dar A.; VENTURIERI, Adriano. "Métricas da paisagem na caracterização da evolução da ocupação da Amazônia". Geografia, v.26, n. 1, 2001.

PIROVANI, Daiani Bernardo; SILVA, Aderbal Gomes da; SANTOS, Alexandre Rosa dos; CECÍLIO, Roberto Avelino; GLERIANI, José Marinaldo; MARTINS, Sebastião Venâncio. "Análise espacial de fragmentos florestais na bacia do rio Itapemirim, ES". Revista Árvore, v. 38, n. 2, p. 271-281, 2014.

RIO GRANDE DO SUL. "Médio Alto Uruguai". Disponível em: <http://www.seplan.rs.gov.br/ download/20130730152141perfil_medio_alto_uruguai. pdf $>$. Acesso em: 21 jul. 2015a.

RIO GRANDE DO SUL. COREDE "Celeiro". Disponível em: <http://www.seplan.rs.gov.br/ download/20130730151920perfil_celeiro.pdf>. Acesso em: 21 jul. 2015b.

ROSA Paulo Afonso da; BREUNIG, Fábio Marcelo; BALBINOT, Rafaelo; GALVÃO, Lênio Soares. "Dinâmica da Floresta do Parque Estadual do Turvo com Índices de Vegetação". Floresta e Ambiente, v. 20, n. 4, p. 487-499, 2013.

ROSA, Paulo Afonso da; BREUNIG, Fábio Marcelo. "Variação temporal de índices de vegetação no Parque Florestal de Nonoai". In: XVII SIMPÓSIO BRASILEIRO DE SENSORIAMENTO REMOTO, 2015, João Pessoa. Anais. João Pessoa: INPE, 2015, p. 627-634.

ROSA, Paulo Afonso da; BREUNIG, Fábio Marcelo; ALMEIDA, Cláudia Maria de; BALBINOT; Rafaelo. "Relação entre população rural e cobertura florestal no noroeste do Rio Grande do Sul". Revista Brasileira de Cartografia, aceito. 2017.

RUSCHEL, Ademir R.; NODARI, Rubens O.; MOERSCHBACHER, Bruno M. "Woody plant species richnessin the Turvo State Park, a large remnant of deciduous Atlantic forest, Brazil". Biodiversity and Conservation, v. 16, p. 1699-1714, 2007.
RUSCHEL, Ademir R.; GUERRA, Miguel P.; MOERSCHBACHER, Bruno M.; NODARI, Rubens O. "Valuation and characterization of the timber species in remnants of the Alto Uruguay River ecosystem, southern Brazil". Forest Ecology and Management, v. 217, p. 103-116, 2005.

SAITO, Nathalia Suemi; MOREIRA, Maurício Alves; SANTOS, Alexandre Rosa dos; EUGENIO, Fernando Coelho; FIGUEIREDO, Álvaro Costa. "Geotecnologia e ecologia da paisagem no monitoramento da fragmentação florestal". Floresta e Ambiente, v. 23, n. 2, p. 201-210, 2016.

SANTOS, Rozely Ferreira dos. Planejamento Ambiental - teoria e prática. São Paulo: Oficina de Textos, 2004.

SANTOS, Rozely Ferreira dos (ORG.). Vulnerabilidade Ambiental - Desastres Naturais ou Fenômenos Induzidos? Brasília: MMA, 2007.

SECRETARIA ESTADUAL DO MEIO AMBIENTE SEMA. Plano de manejo do Parque Estadual do Turvo. Disponível em: <http://www.sema.rs.gov.br/upload/ Plano_manejo_PETurvo.pdf $>$. Acesso em: 15 jan. 2015.

SILVA, Roberto Diego Bezerra da; DELGADO, Rafael Coll; LYRA, Gustavo Bastos; OLIVEIRA JUNIOR, José Francisco de; RODRIGUES, Rafael de Ávila; CARDOZO, Ana Carolina; BRASILEIRO, Felipe Gomes. "Dinâmica espacial e temporal do uso da terra no município de Seropédica, Rio de Janeiro, Brasil'". Revista Geografia Acadêmica, v. 8, n. 1, p. 38-49, 2014.

SILVA, Kmila Gomes da; SANTOS, Alexandre Rosa dos; SILVA, Aderbal Gomes da; PELUZIO, João Batista Esteves; FIEDLER, Nilton César; ZANETTI, Sidney Sára. "Análise da dinâmica espaço-temporal dos fragmentos florestais da sub-bacia hidrográfica do Rio Alegre, ES”. Cerne, v. 21, n. 2, p. 311-318, 2015.

SLAVIERO, L. B.; et al. "Estrutura, configuração e fragmentação da Paisagem na região Norte do Rio Grande do Sul, Brasil”. In: VIII CONGRESSO DE ECOLOGIA DO BRASIL, 2007, Caxambu. Anais. Caxambu, 2007, p. $1-2$.

SOARES FILHO, Britaldo. Modelagem da dinâmica de paisagem de uma região de fronteira de colonização amazônica. 1998. Tese (Doutorado em Engenharia Ci- 
vil) - Escola Politécnica da Universidade de São Paulo, São Paulo.

SOUZA, Guilherme Silvério Aquino de; CONRADO, Vinícius Nascimento; MARTINS, Bruno Ferraz; QUINTO, Vagner Mauri; SILVA, Elias. "Análise temporal da cobertura vegetal no Parque Estadual Cachoeira da Fumaça, ES, por meio de técnicas de sensoriamento remoto". Revista Verde de Agroecologia e Desenvolvimento Sustentável, v. 10, n. 1, p. 103-107, 2015.

UNITED STATES GEOLOGICAL SURVEY (USGS) Landsat missions. Disponível em: < http://landsat.usgs. gov/about_project_descriptions.php >. Acesso em: 25 jun. 2015.

VIANA, V. M.; et al. "Biologia e manejo de fragmentos florestais naturais". In: VI CONGRESSO FLORESTAL BRASILEIRO, 1990, Campos do Jordão. Anais. Campos do Jordão: SBS/SBEF, 1990. p.113-118.

\section{Correspondência dos autores:}

Paulo Afonso da Rosa

e-mail: pauloafonso.darosa@gmail.com

Fábio Marcelo Breunig

e-mail: fabiobreunig@gmail.com

Cláudia Maria de Almeida

e-mail: almeida@dsr.inpe.br

Rafaelo Balbinot

e-mail: rafaelo.balbinot@gmail.com

Artigo recebido em: 21/09/2016

Aceito para publicação em: 14/11/2016 